\title{
Recent microwave research studies of Gazi Biophysics \& Gazi Non-Ionizing Radiation Protection Center
}

\author{
Nesrin Seyhan ${ }^{\mathrm{a}, \mathrm{b}^{*}}$ \\ ${ }^{a}$ Department of Biophysics, Faculty of Medicine, Gazi University, Ankara, Turkey \\ ${ }^{b}$ Gazi Non-Ionizing Radiation Protection Center-GNRP, Ankara, Turkey
}

\section{ARTICLE INFO}

* Correspondence to:

Nesrin Seyhan

Department of Biophysics,

Faculty of Medicine, Gazi University,

Ankara, Turkey

e-mail: nesrin@gazi.edu.tr

\section{Keywords:}

Blood lymphocytes

Breast cancer (mcf-7) cells

Endocrinology

Radiofrequency

\section{ABSTRACT}

Gazi Biophysics is located in Ankara at the Medical Faculty of Gazi University and has been carrying out in vivo and in vitro research studies on the biological impacts of Static, Extremely Low Frequency (ELF) and Microwave (MW) electromagnetic fields (EMF) since 1989. Our laboratory includes: Physicists, biologists, electrical engineers, all of whom are studying how living systems respond to EMF. Our research team includes physicists, biologists, electrical engineers, physicians, biochemists, pathologists and veterinarians.Gazi Biophysics is Academic Representative to NATO Science and Tecnology Organisation (NATO STO HFM) since 2007, International Advisory Committee member of EMF and Health to WHO since 2001, and Scientific Secreteriat Member of International Commission for Electromagnetic Safety (ICEMS) since 2007. We do expose animals and cell cultures to Radiofrequency (RF) EMF including mobile phones and we do clinical research. We also measure all kinds of EMF sources between $5 \mathrm{~Hz}-$ $60 \mathrm{GHz}$, including cellular phones, base stations, transformers, high power lines, TV and radio antennas, Microwave ovens, Diathermy units, Wi-Fi's. Magnetic resonance imaging (MRI)'s, Radars under Gazi Nonionizing Radiation Protection Center (GNRK). GNRK has been founded by Gazi Biophysics in July, 2004. Gazi Biophysics \& GNRK have 70 published articles related with biological effects of EMF. Below, I will present only the results of our recent MW research studies. These studies include Pregnancy Study, DNA Study, Thyroid Study, Oxidative Stress Study, Blood Lymphocytes Study, Mitochondrial Membrane Potential of Breast Fibroblast cells and Breast Cancer (MCF7) cells Study. Pregnancy study( 2007-cont.) (in vivo): In this study, adult, pregnant, newborn and offspring White New Zealand rabbits were exposed to $1800 \mathrm{MHz}$ GSM modulated RFR $(217 \mathrm{~Hz}, 20 \mathrm{dBm}, 14 \mathrm{~V} / \mathrm{m})$ for 7 days, $15 \mathrm{~min} /$ day. We found increased DNA base modification and free radical formation in brain tissue of non-pregnant adults, increased oxidative stress in liver tissue of non pregnant adults, pregnants and 2 days old newborns increased apoptotic cells in the brain (neurons, glial cells) and eye (cornea, lens) tissues of adults, pregnants and newborns increased DNA base modification in liver tissue of female, infants (one month old). There has been 10 published articles on the Pregnancy Study. DNA study (clinical): In this study, 6 women, 2 men (30-47 years old) were exposed to $900 \mathrm{MHz}$ GSM Modulated RFR $217 \mathrm{~Hz}, 577 \mu \mathrm{s}$, from an Apple iphone cupertino, CA mobile phone, with SAR $0.974 \mathrm{~W} / \mathrm{kg}$. Human hairs are plucked within $6 \mathrm{~cm} \times 6 \mathrm{~cm}$ area behind the right ear before and after using $15 \mathrm{~min}$ and 30 min phone call. Modified Comet Assay Technique is used for DNA analysis of the hair root cells.We found significantly increased Single-strand DNA breaks in the hair root cells after using 15 minutes and 30 minutes cellular phone exposure. Thyroid study (in vivo): In this study, 2 months old Wistar rats were exposed to $900 \mathrm{MHz}$ GSM Modulated RFR $(217 \mathrm{~Hz}, 1.35 \mathrm{~W} / \mathrm{kg})$ for 21 days, 15min/day. We found induced hypothyroidism and caspase activation (indicator of apoptosis). Oxidative stress study (in vivo): In this study, 2 months old Wistar rats were exposed to $900 \mathrm{MHz}$ GSM Modulated RFR $(217 \mathrm{~Hz}, 1.35 \mathrm{~W} / \mathrm{kg})$ for 21 days, $15 \mathrm{~min} /$ day. We found oxidative damage in liver, heart, lung and testis tissues. Blood lymphocytes study (in vitro): In this study, human 
peripheral blood lymphocyte cells were exposed to $1800 \mathrm{MHz}$ GSM Modulated RFR $(217 \mathrm{~Hz}, 0.21 \mathrm{~W} / \mathrm{kg}$ ) for $6,8,24$ and $48 \mathrm{~h}$. We found inhibited cell proliferation, increased Sister Chromatid Exchange frequency (indicator of DNA damage) Mitochondrial membrane potential of breast fibroblast cells and breast cancer (MEF-7) cells studies (in vitro): In these studies, Breast Fibroblast and MCF-7 cells were exposed to $2.1 \mathrm{GHz}$ MW for $4 \mathrm{~h}$ and $24 \mathrm{~h}$. We found decreased viability of Breast Fibroblast and MCF-7 cells, increased apoptotic activities of Breast Fibroblast and MCF-7 cells, decreased Mitochondrial Membrane Potential $(\Delta \Psi \mathrm{m})$ in Breast Fibroblast cells, increased Mitochondrial Membrane Potential $\left(\Delta \Psi_{\mathrm{m}}\right)$ and cytochrome-c level in MCF-7 cells. Endocrinology study (in vivo): In this study, rats were exposed to $1800 \& 2100 \mathrm{MHz}$ RFR for 1 or 2 months. We found decreased melanocyte-stimulating hormone level(MSH) and delay on the satiety feeling. Skin hydroxyproline study (in vivo): Two months old male wistar rats were exposed to $900-\mathrm{MHz}$ pulse-modulated RFR at an average whole body SAR of $1.35 \mathrm{~W} / \mathrm{kg}$ for 3 weeks, for $20 \mathrm{~min} /$ day. Skin (abdominal costa) hydroxyproline level analyzed with LC/MS MS technique. We found significantly increased in skin hydroxyproline level. Ongoing studies: Effect of multi-frequency EMF ( $50 \mathrm{~Hz} \& 2100 \mathrm{MHz}$ ) on the permeability of blood brain barrier of non-diabetic\&diabetic rats. Effects of chronic RFR exposure on the organs of female and male rats with melatonin injection. $2100 \mathrm{MHz}$ RFR exposure leads structural changes on the genital ducts of male rats (completed, not published yet). Evaluation of reactive oxygen species (ROS) production and antioxidant properties of black, green, sage and roseship tea by spin trapping electron spin resonance (ESR) spectroscopy in normal and malignant lymphocytes exposed to UV radiation.

J. Exp. Clin.Med., 2013; 30: 271-272 